\title{
Effects of Polymerization Mode and Interaction with Hydroxyapatite on the Rate of pH Neutralization, Mechanical Properties, and Depth of Cure in Self-Adhesive Cements
}

\author{
Fabiana S. A. S. Camargo ${ }^{1}$ Alejandra H. M. González² \\ Paulo H. P. D’Alpino \\ ${ }^{1}$ Department of Dentistry, Dental School, Universidade Anhanguera \\ de São Paulo, São Paulo, Brazil \\ 2Biotechnology and Innovation in Health Program, Universidade \\ Anhanguera de São Paulo, São Paulo, Brazil \\ ${ }^{3}$ Department of Dentistry, School of Dentistry, Metropolitan \\ University of Santos, Santos, São Paulo, Brazil \\ ${ }^{4}$ Technological Research Center, School of Dentistry, University of \\ Mogi Das Cruzes, Mogi Das Cruzes, São Paulo, Brazil \\ ${ }^{5}$ Department of Dentistry, Dental School, São Leopoldo Mandic, \\ São Paulo, Brazil
}

Eur J Dent 2019;13:178-186
Roberta C. B. Alonso ${ }^{3,4}$ Vinicius Di Hipólito ${ }^{5}$

Address for correspondence Paulo H. P. D’Alpino, DDS, MSc, PhD, Avenida Raimundo Pereira de Magalhães, 3.305 Vila Iris, São Paulo, SP Brazil, CEP 05145-200 (e-mail: paulodalpino@yahoo.com).

\begin{abstract}
Keywords

- activation mode

- hydroxyapatite

- mechanical properties

- self-adhesive resin cements

Objective The aim of the study was to evaluate the physicochemical properties of self-adhesive resin cements associated with hydroxyapatite (HAp) according to the polymerization activation.

Materials and Methods Specimens of cements (PermaCem 2.0 [DMG]; MaxCem Elite [Kerr], and RelyX U200 [3M ESPE]) were distributed into three groups: activation mode; self-cured and dual-cured modes; and association or not with HAp powder mode. The $\mathrm{pH}$ neutralization was evaluated as a function of time. Flexural strength and elastic modulus were also tested $(0.5 \mathrm{~mm} / \mathrm{min}$.). The depth of cure was also analyzed using the scraping test (ISO 4049). Infrared spectroscopy was also used to collect the spectra of specimens to evaluate the chemical bonds. Statistical comparisons were conducted at $5 \%$ of significance.

Results The aggressiveness of the self-adhesive resin cements evaluated varied among the materials with a tendency for neutralization. Self-cure groups exhibited lower $\mathrm{pH}$ throughout the entire evaluation when compared with that of the dual-cure ones, irrespective of the addition of HAp. MaxCem Elite when photoactivated was the only cement influenced by the addition of the HAp in terms of mechanical properties. The self-adhesive cements tested presented equivalent depth of cure based on the ISO 4049 requirements, regardless of the evaluated factors.

Conclusions Based on the parameters evaluated, the results demonstrated that most of the self-adhesive cements remained unaltered or improved when mixed with $\mathrm{HAp}$, regardless of the activation mode.
\end{abstract}

\section{Introduction}

The self-adhesive, dual-polymerizing resin luting cements are gaining increasing popularity, mainly due to the simplification of the luting procedure and reduction in the postoperative sensitivity. These cements require no pretreatment of the dental structure before the cementation procedure, thus decreasing the number of operatory steps
DOI https://doi.org/ 10.1055/s-0039-1696057 ISSN 1305-7456.
C2019 Dental Investigation Society
License terms

(요 (1) $\odot \circledast$ 
involved. ${ }^{1,2}$ So, this category of resin cements became the material of choice for many clinicians and a variety of commercial self-adhesive resin cements is currently available.

In general, self-adhesive cements are composed of methacrylate monomers modified by acidic functionalities that allow demineralization and infiltration of the dental substrate $^{3,4}$ resulting in micromechanical retention after in situ polymerization. At the same time, the acidic groups could interact with the calcium of the hydroxyapatite (HAp), providing chemical binding with the tooth structure. ${ }^{1,4}$ If, on one hand, the self-adhesive cements are user-friendly, on the other hand their setting involves a complex dynamic mechanism. ${ }^{5}$ The basic F-Al-Si-based inorganic fillers in self-adhesive cements react with the functional acidic monomers. ${ }^{6}$ Therefore, the main setting reaction occurs via free-radical polymerization, initiated either by a curing light or by a redox system, allowing the setting polymerization reaction in this acidic environment. ${ }^{?}$

The conditions of such dynamic setting mechanism, mainly regarding the activation mode of the polymerization reaction (chemical or dual) and pHneutralization behavior, possible affect the properties of the self-adhesive cements. ${ }^{8}$ In general, the degree of conversion for the dual-cure activation mode is higher than the self-cure, irrespective of the time. ${ }^{9}$ Discrepancies in conversion degree between the dual and self-cure modes from 11 to $79 \%$ were also found. ${ }^{7}$ Clinically, there may be situations in which the light from the light-curing unit is greatly attenuated by the overlying indirect restoration. In addition, by increasing the tip-to-tooth distance the light dispersion, the bonding of indirect composite restorations may be severely affected.

Concerns have been previously raised as to whether self-adhesive resin cements can be successfully used in clinical applications because lower-end conversions are obtained in a self-curing mode in the case of light attenuation. ${ }^{10}$ The rate at which the acidity of self-adhesive cements is neutralized is claimed to play a crucial role on the immediate and long-term mechanical stability of the material. ${ }^{5}$ Self-adhesive resin cements with faster $\mathrm{pH}$ neutralization were demonstrated to be less prone to degradation of flexural strength after thermocycling. ${ }^{11}$ Besides using an automix delivery system, the contact with the HAp of the tooth structure during the setting reaction has been regarded as being essential to accelerate the $\mathrm{pH}$ neutralization. ${ }^{12}$ In this way, it could be speculated that, in the clinical conditions in the absence of HAp (i.e., when cementing an indirect restoration over a core resin-based material), the performance of the self-adhesive resin cement would be affected.

In the present study, the influence of acidic monomer/ HAp chemical reaction on the physicochemical properties of self-adhesive resin cements was investigated by employing commercial self-adhesive resin cements. These cements are methacrylated phosphoric esters-based and seem to differ in aggressiveness. Considering the differences in their acidity, it is imperative to investigate the role of their aggressiveness in the acidic monomer/HAp reaction as well as their polymerization behaviors. ${ }^{13}$ In this way, HAp powder was incorporated in the cements to mimic the dentin demineralization or interaction with the dental tissues. This in vitro study aimed to understand the correlation of the acidic monomer/HAp reaction with the polymerization behavior of self-adhesive resin cements with different aggressiveness. For that, the influence of the activation mode (dual or self-cure) and the association of the cements with HAp were evaluated in terms of $\mathrm{pH}$ neutralization rate, flexural strength, elastic modulus, depth of cure, and the chemical bonds. The null hypothesis tested was that there analyzed parameters among the cements tested would be negatively affected by the activation mode and the incorporation of HAp.

\section{Materials and Methods}

\section{Specimen Fabrication}

Three commercial self-adhesive resin cements (PermaCem 2.0 [DMG]; MaxCem Elite [Kerr] and RelyX U200 [3M ESPE]) were selected for this study (-Table 1). Twelve experimental groups were developed as functions of the polymerization mode and the association of the cements with the HAp powder: (1) selfcured mode; (2) self-cured mode associated with HAp; (3) dualcured mode, and (4) dual-cured mode associated with HAp. The unpolymerized resin cements were manipulated according to the manufacturers' instructions and then placed into a Teflon mold positioned over a polyester strip. After filling the mold to excess, the material surface was covered with a Mylar strip and a glass slide and compressed to extrude excess material. The glass slide was then removed, leaving the Mylar strip. The specimens of the dual-cured groups were then photoactivated. The light-curing procedure was performed using a light-emitting

Table 1 Materials tested in this study (manufacturer information)

\begin{tabular}{|l|l|l|}
\hline Material & Composition & Delivery system \\
\hline $\begin{array}{l}\text { PermaCem 2.0 } \\
\text { DMG, Hamburg, }\end{array}$ & $\begin{array}{l}\text { lonomer glass in a bis-GMA matrix of dental resins, activator, catalyst, } \\
\text { additives }\end{array}$ & Automix \\
\hline $\begin{array}{l}\text { Maxcem Elite } \\
\text { Kerr Italia, Scafati, Italy }\end{array}$ & $\begin{array}{l}\text { Methacrylate ester monomers, inert mineral fillers, Ytterbium Fluoride, acti- } \\
\text { vators, stabilizers and colorants }\end{array}$ & Automix \\
\hline $\begin{array}{l}\text { RelyX U200 } \\
\text { 3M ESPE, St. Paul, } \\
\text { Minnesota, United States }\end{array}$ & $\begin{array}{l}\text { Silane treated glass powder, substituted dimethacrylate, 1-benzyl-5-phe- } \\
\text { nyl-barbic-acid, calcium salt, 1,12-dodecane, dimethacrylate, sodium } \\
\text { p-toluene sulfinate, silane treated silica, calcium hydroxide, methacrylated } \\
\text { aliphatic amine, titanium dioxide }\end{array}$ & Automix \\
\hline
\end{tabular}


diode light-curing unit (Radii; SDI, Bayswater, Victoria, Australia) with an irradiant emittance of $1400 \mathrm{~mW} / \mathrm{cm}^{2}$. The distal end of the curing light guide was placed on the top Mylar surface. The light output was monitored using a handheld radiometer (Model 100, Demetron Research Corp., Danbury, Connecticut, United States) before and during testing. After the photoactivation procedures (dual-cure groups), the specimens were removed from the molds and stored in lightproof containers for 24 hours at room temperature $\left(22^{\circ} \mathrm{C}\right)$. The specimens of the self-cure groups were kept in the molds for 24 hours at room temperature in the dark, prior to their removal. Specimens of the groups in which the cements are associated with HAp were obtained by mixing a portion of dry HAp powder with self-adhesive cements as previously described. ${ }^{5}$ For that, a crystalline and pure $\mathrm{HAp}\left(\mathrm{Ca}_{10}\left[\mathrm{PO}_{4}\right]_{6}[\mathrm{OH}]_{2}\right)$ was used (JHS Biomaterials, Sabará, MG, Brazil). According to the results of a previous study, ${ }^{5}$ the peaks and associated planes of HA diffractograms matched the crystallographic data sheet (74-0565) of calcium hydroxide phosphate $\left(\mathrm{Ca}_{10}[\mathrm{PO} 4]_{6}[\mathrm{OH}]_{2}\right)$ obtained from the PCPDFWIN database. In accordance with this database, the crystalline pattern has a hexagonal cell with the following parameters: $\mathrm{a}=9.424 \AA$ and $\mathrm{c}=6.879 \AA .{ }^{5}$ proving the purity of the HAp powder.

\section{$\mathrm{pH}$ of the Eluate}

Specimens of cements ( $2 \mathrm{~mm}$ thick, $6 \mathrm{~mm}$ in diameter) were individually immersed in $10 \mathrm{~mL}$ of distilled water $(\mathrm{pH}=6)$. Baseline $\mathrm{pH}$ of the water was measured using a digital pHmeter (Digimed DM 20, Digimed, Campo Grande, MS, Brazil). The discs were immersed in water and $\mathrm{pH}$ readings of the eluates were repeatedly performed after $5,15,30,60,120$, $240,360,720$, and 1440 minutes after immersion $(n=3) .^{12}$

\section{Flexural Strength and Elastic Modulus}

Specimens of cements were also obtained according to the four experimental groups as previously described using barshaped Teflon molds $(7 \times 2 \times 1 \mathrm{~mm})$. Prior to the test, the specimen dimensions were measured using a digital caliper (Digimatic Caliper CD, Mitutoyo, Japan). A three-point bending test was performed in a universal testing machine (Instron model 3342, Instron Corp., Canton, Massachusetts, United States) at $0.5 \mathrm{~mm} / \mathrm{min}$ and $5 \mathrm{~mm}$ span between supports.

To calculate the flexural strength $(\sigma)$, it was used the equation, as follows ${ }^{14}$ :

$$
\sigma=\frac{3 F \times L}{2 b \times h^{2}}
$$

To calculate the flexural modulus $(E)$, the following equation was used ${ }^{14}$ :

$$
E=\frac{L^{3}}{4 b \times h^{3}} \times \frac{F}{Y}
$$

where $F$ is the maximum strength in $\mathrm{N} ; L$ the distance between the rests; $b$ the width of the specimen; $h$ the height of the specimen; and $\mathrm{F} / \mathrm{Y}$ the slope of the linear part of the stress-strain curve. ${ }^{14}$

\section{Depth of Cure}

Depth of cure was analyzed by the scraping method $(n=3)$. The specimens of the cements were obtained according to the four experimental conditions as previously described and placed into a Teflon mold (4 mm diameter, $6 \mathrm{~mm}$ height). In the photoactivated groups, the cements were irradiated through a polyester strip according to the manufacturers' instructions. After the photoactivation procedures (dual-cure groups), the specimens were stored in lightproof recipients for 24 hours at room temperature $\left(22^{\circ} \mathrm{C}\right)$. The specimens of the self-cure groups were kept in the molds for 24 hours at room temperature in the dark prior to their testing. The specimens were removed from the molds and the uncured material was then scraped away with a plastic spatula. The length of the remaining material was measured with a digital micrometer in three areas and an average length was then calculated. This average result was finally divided by two to obtain the depth of cure in accordance with the ISO 4049. Means and standard deviations of depth of cure of the experimental groups were calculated.

\section{Fourier Transform Infrared Analysis}

The chemical bonds of cement specimens were analyzed by spectroscopic technique. For that, Fourier transform infrared (FTIR) analysis was performed (Bruker Vertex 70 FTIR Spectrometer (Bruker Optik GmbH, Ettlingen, Germany) with the wavelength ranging from 4,000 to $400 \mathrm{~cm}^{-1}$. Spectra of the polymerized material were obtained by placing the materials directly against the diamond crystal localized of the ATR attachment. Infrared spectra of polymerized products were obtained using 16 scans at a resolution of $4 \mathrm{~cm}^{-1}$. Three replications were made for each test condition.

\section{Statistical Analysis}

The data of flexural strength and elastic modulus were submitted to two-way analysis of variance (factors: activation mode and association with HAp) and Tukey test. For all analyses, $p<0.05$ was considered statistically significant.

\section{Results}

The $\mathrm{pH}$ profiles for all tested materials according to the experimental groups are displayed in $\mathbf{- F i g . ~ 1}$. In general, the rate of $\mathrm{pH}$ neutralization observed for all of the cements was similar, irrespective of the activation mode and mixing with HAp. The initial pH values of the cements PermaCem 2.0 and MaxCem Elite were lower than that of observed for RelyX U200. The $\mathrm{pH}$ neutralization, the photoactivation, and the presence of HAp accelerated the $\mathrm{pH}$ neutralization, mainly in the first 30 minutes. Then, the $\mathrm{pH}$ neutralization profile of all of PermaCem 2.0 groups was very similar. The same was observed for MaxCem Elite that exhibited similar $\mathrm{pH}$ neutralization profile, especially for the control groups. For the cement RelyX U200, neither the photoactivation nor the addition of HAp influenced the $\mathrm{pH}$ neutralization. It was clearly demonstrated that the differences in the $\mathrm{pH}$ neutralization between 


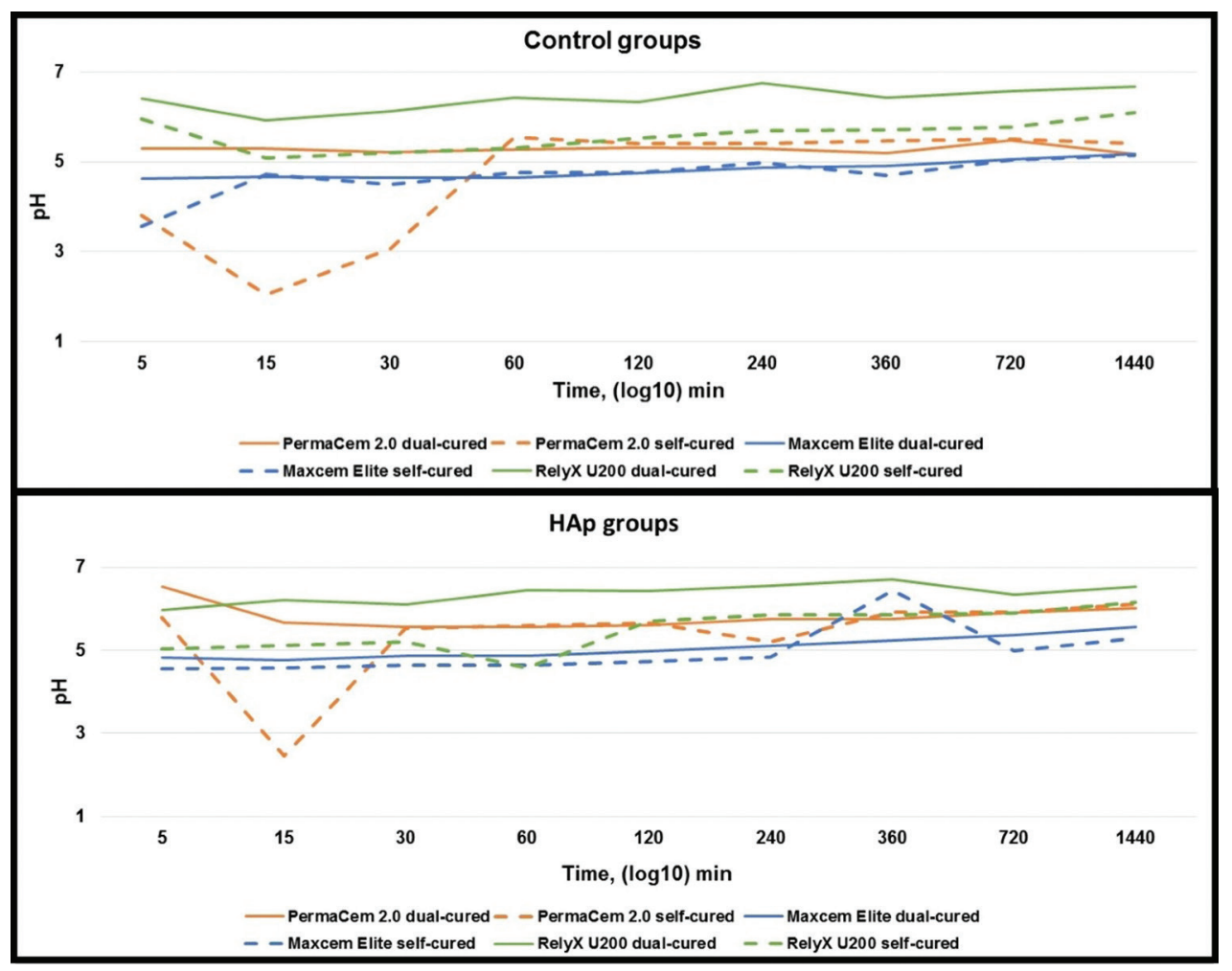

Fig. $1 \mathrm{pH}$-neutralization rate profiles of the self-adhesives resin cements investigated according to the polymerization condition and the addition of hydroxyapatite.

Table 2 Flexural strength (standard deviation) of the resin cements in MPa submitted to the polymerization conditions investigated

\begin{tabular}{|l|l|l|}
\hline Materials & Control & With Hap \\
\hline PermaCem 2.0 dual-cured & $38.0(7.2)$ b, A & $85.7(16.0)$ a, A \\
\hline PermaCem 2.0 self-cured & $46.3(10.6)$ b, A & $64.5(17.3)$ a, A \\
\hline MaxCem Elite dual-cured & $75.6(9.5)$ b, B & $42.0(7.0)$ a, A \\
\hline MaxCem Elite self-cured & $58.0(20.9)$ a, B & $54.4(14.4)$ a, A \\
\hline RelyX U200 dual-cured & $31.6(10.7)$ b, A & $81.6(16.5)$ a, A \\
\hline RelyX U200 self-cured & $66.6(13.5)$ a, B & $73.4(14.2)$ a, A \\
\hline
\end{tabular}

Note: $n=7$

Different letters, lower case for line, and upper case for column (comparing the same materials): significant $(p<0.05)$.

the dual-cure and self-cure groups, in which the latter one exhibited lower $\mathrm{pH}$ throughout the entire evaluation.

The results of flexural strength and elastic modulus are displayed in the - Tables 2 and $\mathbf{3}$, respectively. The highest flexural strength mean was noted for PermaCem 2.0 associated with HAp when immediately photoactivated (85.7 MPa), and the lowest for RelyX U200 when chemically activated (31.6 MPa). When the resin cement PermaCem 2.0 dual-cured was associated with HAp, the means of flexural strength were significantly higher when compared with that of control cements $(p<0.001)$. The same was observed for RelyX U200 when dual-cured, exhibiting a significantly higher mean when associated with $\operatorname{HAp}(p<0.001)$. On the other hand, HAp had no influence in the flexural strength means for the cements MaxCem Elite and RelyX U200 when self-cured $(p=0.132)$. In addition, the flexural strength of MaxCem
Elite significantly decreased when mixed with HAp when immediately photoactivated (dual-cured mode) $(p<0.001)$. Comparing the influence of the curing mode among the resin cements tested, RelyX U200 was the only material influenced by the curing modes. The self-cured material presented significantly lower means when compared with that of dual-cured group $(p<0.001)$. When associated with HAp, no significance was observed when both curing mode groups were compared $(p=0.145)$.

The highest flexural modulus mean was observed for RelyX U200 group (1.7 GPa) and the lowest for MaxCem Elite (1.6 GPa) when both materials were dual-cured $(-$ Table 3 ). The results of the cement PermaCem 2.0 were not influenced by both factors HAp and curing mode $(p>0.325)$. The same occurred with RelyX U200. MaxCem Elite was the only exception in which the dualcured cement exhibited significantly lower elastic modulus 
Table 3 Elastic modulus (standard deviation) of the resin cements in GPa submitted to the polymerization conditions and the association with HAp investigated

\begin{tabular}{|l|l|l|}
\hline Materials & Control & With HAp \\
\hline PermaCem 2.0 dual-cured & $5.5(1.0) \mathrm{a}, \mathrm{A}$ & $3.9(0.5) \mathrm{a}, \mathrm{A}$ \\
\hline PermaCem 2.0 self-cured & $4.4(0.7) \mathrm{a}, \mathrm{A}$ & $4.7(0.8) \mathrm{a}, \mathrm{A}$ \\
\hline MaxCem Elite dual-cured & $5.0(0.7) \mathrm{b}, \mathrm{A}$ & $1.6(0.3) \mathrm{a}, \mathrm{B}$ \\
\hline MaxCem Elite self-cured & $3.1(0.5) \mathrm{a}, \mathrm{B}$ & $3.3(0.2) \mathrm{a}, \mathrm{A}$ \\
\hline RelyX U200 dual-cured & $6.3(1.3) \mathrm{a}, \mathrm{A}$ & $4.8(1.1) \mathrm{a}, \mathrm{A}$ \\
\hline RelyX U200 self-cured & $4.3(0.7) \mathrm{a}, \mathrm{B}$ & $4.6(1.7) \mathrm{a}, \mathrm{A}$ \\
\hline
\end{tabular}

Note: $n=7$.

Different letters, lower case for line and upper case for column (comparing the same materials): significant $(p<0.05)$.

Table 4 Depth of cure (standard deviation) in $\mathrm{mm}$ of the resin cements according to the polymerization condition and the association with $\mathrm{HAp}$

\begin{tabular}{|l|l|l|}
\hline Materials & Control & With HAp \\
\hline PermaCem 2.0 dual-cured & $6.03(0.21) \mathrm{a}, \mathrm{A}$ & $6.30(0.10) \mathrm{a}, \mathrm{A}$ \\
\hline PermaCem 2.0 self-cured & $6.06(0.12) \mathrm{a}, \mathrm{A}$ & $6.12(0.04) \mathrm{a}, \mathrm{A}$ \\
\hline Maxcem Elite dual-cured & $6.36(0.18) \mathrm{a}, \mathrm{A}$ & $6.36(0.12) \mathrm{a}, \mathrm{A}$ \\
\hline Maxcem Elite self-cured & $5.87(0.19) \mathrm{a}, \mathrm{A}$ & $5.92(0.14) \mathrm{a}, \mathrm{A}$ \\
\hline RelyX U200 dual-cured & $6.00(0.20) \mathrm{a}, \mathrm{A}$ & $6.31(0.11) \mathrm{a}, \mathrm{A}$ \\
\hline RelyX U200 self-cured & $6.05(0.15) \mathrm{a}, \mathrm{A}$ & $5.73(0.08) \mathrm{a}, \mathrm{A}$ \\
\hline
\end{tabular}

Note: $n=3$.

Similar letters, lower case for line and upper case for column: not significant $(p>0.05)$.

in the presence of HAp $(p<0.001)$. Despite the changes in the mechanical properties induced by the activation modes and the addition of HAp to the cements, the results of the depth of cure according to ISO 4049 showed no significance among the experimental groups (-Table 4 ). This demonstrates that the depths of cure were similar in all of the experimental groups evaluated, irrespective of the evaluated factors $(p=0.203)$.

-Figure 2A-C illustrates the spectra of three self-adhesive resin cements with and without the incorporation of HAp. In this figure, the spectra of self-adhesive cements according to the curing protocol and to the association with HAp are demonstrated allowing the identification of chemical bonds. The vibrational spectra of samples in the range between 3690 and $3160 \mathrm{~cm}^{-1}$ obtained in all the groups were demonstrated in the same scale of relative absorbance. In the - Table 5, the infrared frequencies and band assignments observed in the self-adhesive resin cements are also presented. Based on these results, it was found that the absorbance (or the height) of $1,715 \mathrm{~cm}^{-1}$ band remained almost unchanged irrespective of the factors analyzed. This band at $1715 \mathrm{~cm}^{-1}$ can be attributed to the stretching of $\mathrm{C}=\mathrm{O}$ bond. The results also indicated that, despite the addition of HAp, the spectral changes were slightly different in the phosphate region ( 900-1100 $\left.\mathrm{cm}^{-1}\right)$. After mixing with HAp, the absorbance of $1074 \mathrm{~cm}^{-1}\left(\mathrm{HPO}_{4}^{2-}\right.$ stretching) and $1034 \mathrm{~cm}^{-1}$ band $\left(\mathrm{PO}_{4}{ }^{3-}\right.$ stretching) changes were mostly observed for MaxCem Elite when self-cured. These spectral changes suggested the chemical reaction of HAp with this self-adhesive cement. Conversely, this spectral change was not seen for
PermaCem 2.0 and RelyX U200, in which the spectra in the phosphate region were similar before and after the HAp mixing. Around $1020 \mathrm{~cm}^{-1}$, there is a band associated with asymmetric stretching $\left(v_{\text {ass }}\right)$ of $\mathrm{PO}_{4}{ }^{3-i o n s}$; in the region of $938 \mathrm{~cm}^{-1}$, some groups exhibited a band that refers to the symmetrical stretching $\left(v_{\text {sim }}\right)$ of these ions. Although it was not possible to establish a comparison with the spectrum of HAp, it was possible to note the elevated spectral absorbance that was mainly due to overlapping with the major bands of HAp (1028 $\left.\mathrm{cm}^{-1}\right)$ and of the $\mathrm{PO}_{4}^{3-}$ stretching $\left(1092 \mathrm{~cm}^{-1}\right)$. Still, in the range of 1250 to $700 \mathrm{~cm}^{-1}$, characteristic bands are observed representing the stretching and disfiguration of $\mathrm{C}-\mathrm{C}$ bonds. Besides these bands, there is an overlapping of bands in the region between 1200 and $800 \mathrm{~cm}^{-1}$, supposedly related to the presence of silicates links. Another overlapping was observed in the region of the absorbance of $1637 \mathrm{~cm}^{-1}$ band. The decrease in the absorbance at $1637 \mathrm{~cm}^{-1}$ possibly indicates consumption of methacrylate $\mathrm{C}=\mathrm{C}$ bonds during the polymerization process. ${ }^{15}$ However, in this same region of the spectra, the groups in which the HAp was added, other characteristic bands that represent the vibration bands of $\mathrm{PO}_{4}{ }^{3}$-are observed. Other bands $\left(3380,2940\right.$, and $2360 \mathrm{~cm}^{-1}$ ) seem to be related to technical artifacts (surface moisture adsorption by the specimens, presence of $\mathrm{CO}_{2}$, among others).

\section{Discussion}

In the present study, it was found that the polymerization mode of the self-adhesive cements and their interaction with 

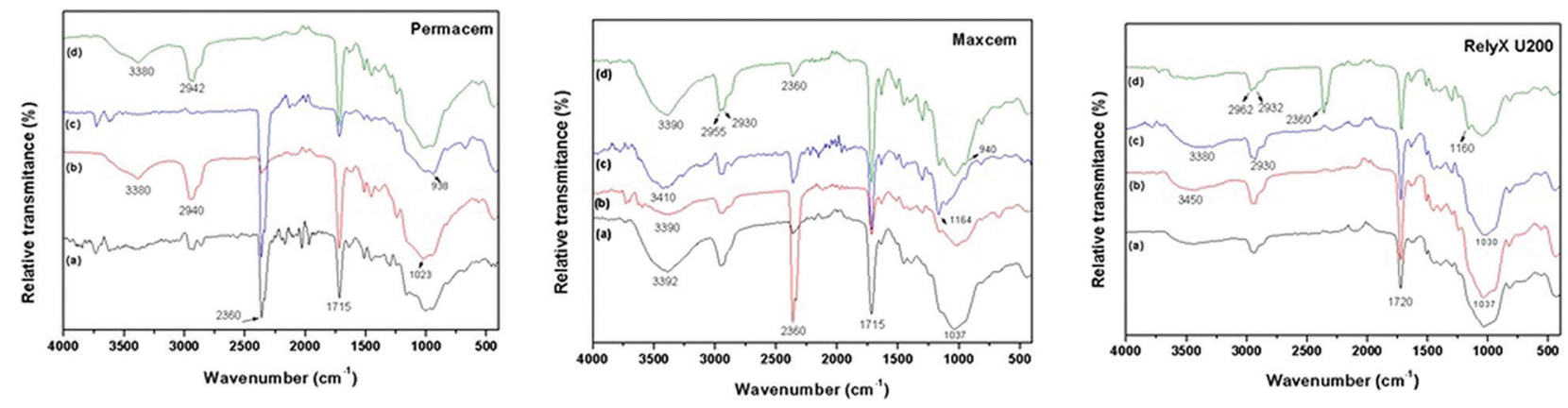

Fig.2 Representative Fourier transform infrared spectra of samples: (a) dual-cured, (b) dual-cured with hydroxyapatite, (c) self-cured, and (d) self-cured with hydroxyapatite.

Table 5 Infrared frequencies and band assignments of self-adhesive resin cements characterized

\begin{tabular}{|c|c|c|c|c|c|c|c|c|c|c|c|c|}
\hline \multicolumn{12}{|c|}{ Wavenumber $\left(\mathrm{cm}^{-1}\right)$} & \multirow[t]{3}{*}{ Band assignment } \\
\hline \multicolumn{4}{|c|}{ PermaCem 2.0} & \multicolumn{4}{|c|}{ MaxCem Elite } & \multicolumn{4}{|c|}{ RelyX U200 } & \\
\hline a & $\mathrm{b}$ & c & d & a & $\mathrm{b}$ & c & d & a & b & c & d & \\
\hline- & 3380 & - & 3380 & 3392 & 3390 & 3410 & 3390 & 3480 & 3450 & 3480 & - & $\mathrm{vO}-\mathrm{H}$ \\
\hline- & - & - & - & - & 2957 & - & 2955 & - & - & 2960 & 2962 & v C-H \\
\hline 2942 & 2940 & - & 2942 & 2940 & 2928 & 2945 & 2930 & 2943 & 2944 & 2928 & 2932 & v C-H \\
\hline 2360 & 2361 & 2361 & - & 2360 & 2360 & 2360 & 2360 & - & - & - & 2360 & $\mathrm{v} \mathrm{CO}_{2}$ \\
\hline 1715 & 1716 & 1715 & 1715 & 1715 & 1715 & 1715 & 1715 & 1720 & 1720 & 1718 & 1718 & $v \mathrm{C}=\mathrm{O}$ \\
\hline \multirow[t]{5}{*}{$\begin{array}{l}1250- \\
700\end{array}$} & $\begin{array}{l}1250- \\
700\end{array}$ & $\begin{array}{l}1250- \\
700\end{array}$ & $\begin{array}{l}1250- \\
700\end{array}$ & $\begin{array}{l}1250- \\
700\end{array}$ & $\begin{array}{l}1250- \\
700\end{array}$ & $\begin{array}{l}1250- \\
700\end{array}$ & $\begin{array}{l}1250- \\
700\end{array}$ & $\begin{array}{l}1250- \\
700\end{array}$ & $\begin{array}{l}1250- \\
700\end{array}$ & $\begin{array}{l}1250- \\
700\end{array}$ & $\begin{array}{l}1250- \\
700\end{array}$ & Silicates \\
\hline & & & & & & & & & & & & $\mathrm{v}_{\text {asy }} \mathrm{PO}_{4}$ \\
\hline & & & & & & & & & & & & $\mathrm{v}_{\text {sym }} \mathrm{PO}_{4}$ \\
\hline & & & & & & & & & & & & v C-C \\
\hline & & & & & & & & & & & & $\delta C-C$ \\
\hline
\end{tabular}

Abbreviations: a, dual-cured; b, dual-cured with HAp; c, self-cured; d, self-cured with Hap; $v$, stretching vibration; $v_{\text {asy; }}$ asymmetric stretching; $v_{\text {sym }}$, symmetric stretching; $\delta$, bending vibration.

HAp influenced the analyzed parameters in different ways depending on the material. In this way, the research hypothesis anticipating that the curing conditions, regarding the activation mode and mixing with HAp would negatively affect the physicochemical properties of the self-adhesive cements evaluated, were upheld by the experimental data.

The chemical reaction and interaction with HAp and the polymerization seems to be dependent on the aggressiveness of the resin cements tested, which is determined by the composition and functional monomer(s) concentration in the material. In this way, the functional, acidic monomers/dental mineral interaction of a certain cement, which is the main characteristic of this category of cements, may lead to different penetrating into dentin smear layers and the depth of demineralization. ${ }^{15}$ In addition, depending on their aggressiveness, which is usually quantified by the $\mathrm{pH}$ value, ${ }^{15}$ the self-adhesive cements are able to dissolve/demineralize the smear layer/plugs and produce different etching patterns. ${ }^{16}$ On the other hand, self-etching adhesives with different aggressiveness may present distinct polymerization behaviors. For that, as previously pointed out, it is imperative to have a formula in which the polymerization reaction proceeds in an acidic environment without interfering in the end conversion. ${ }^{5,17}$ The polymerization setting reaction is claimed to be responsible for $\mathrm{pH}$ neutralization in the polymerizing material, ${ }^{1}$ which plays an important role on the immediate and long-term mechanical properties of the material. ${ }^{11}$ So, the study of such $\mathrm{pH}$ neutralization over time is imperative for a better understanding of the properties of each commercial SRC.

In the present study, the initial low $\mathrm{pH}$ of the eluate observed for the cements can be attributed by the elution of unpolymerized acidic methacrylates. ${ }^{6}$ The variation in the $\mathrm{pH}$ after manipulation and association or not with HAp was evaluated to find out the role of the aggressiveness of the cements in the acidic monomer/HAp reaction as a function of the activation mode. For the cements PermaCem 2.0 and MaxCem Elite the activation mode, especially the immediate photoactivation, when associated with HAp accelerated the $\mathrm{pH}$ neutralization, mainly in the first 30 minutes. For the cement RelyX U200, none of the factors (activation mode and HAp) seemed to influence the $\mathrm{pH}$ neutralization. In spite of these differences, the $\mathrm{pH}$ values of all of the experimental groups tended to neutralization. 
The resin cement RelyX U200 was the only cement investigated that the $\mathrm{pH}$ neutralization rate was similar when photoactivated, irrespective of the addition of HAp. Moreover, this was the material that reached the highest levels of neutralization in the first 24 hours, in which the $\mathrm{pH}$ was higher than 6.0. Probably, such favorable neutralization behavior is due to the incorporation of calcium hydroxide in the composition of RelyX U200 by the manufacturer ( - Table 1; 3M ESPE, St. Paul, Minnesota, United States). RelyX U200 is the only cement that the manufacturer claims to include calcium hydroxide in its formulation. ${ }^{1}$ It can be also highlighted for RelyX U200 that the aggressiveness of the self-cure groups seems to be higher than that of dual-cure groups, considering that the $\mathrm{pH}$ was lower throughout the entire evaluation in comparison with the dual-cure groups (-Fig. 1). The results of $\mathrm{pH}$ variation rate as a function of the time showed that materials differed in their initial and final acidity, demonstrating that $\mathrm{pH}$ neutralization behavior is not homogeneous among representative materials of this class. These results were in accordance with previous studies, ${ }^{18,19}$ which also investigated $\mathrm{pH}$ development of self-adhesive cements over time. Although the absolute $\mathrm{pH}$ values from the mentioned studies are different from that presented in this study, RelyX Unicem and RelyX U200 present similar diffusion-controlled $\mathrm{pH}$ rise and the same basic composition, presenting higher 24 hours $\mathrm{pH}$ values compared with that of Maxcem Elite.

Differences in the absolute $\mathrm{pH}$ values observed in the present study can be related to the $\mathrm{pH}$ evaluation method. The $\mathrm{pH}$ measurement is a very sensitive technique and the outcome strongly relates with the chosen setup. Testing temperature also plays an important role on the measured $\mathrm{pH}$, as water equilibrium constant is dependent upon the temperature. In addition, the chosen amount of electrolyte volume strongly determined the $\mathrm{pH}$ value in terms of higher values at increased volumes. The previous studies set distinct measurement intervals and the rinsing of the specimens before each measurement, which is ideal. This procedure certainly rinses off the acidic components and a highly neutral $\mathrm{pH}$ (close to $\mathrm{pH}$ 7) that can be finally measured. The investigated $\mathrm{pH}$ values were collected in continuous measurements, as previously described. ${ }^{12}$ In addition, it is important to highlight that the $\mathrm{pH}$ tested set up considered not only the acidbase reaction of the cement but also possible acid-base-interactions between the material and HAp, which also plays an important role in $\mathrm{pH}$ neutralization. Based on the results, it can be inferred that the neutralization behavior differs among the materials tested as the varied components in the formulation regulate the acid-base-reaction.

According to the results of the mechanical properties (-Tables 2 and $\mathbf{3}$ ), the only material negatively affected by the presence of HAp was the cement MaxCem Elite when photoactivated. For the other groups, HAp positively improved or had no influence in the flexural strength means. Although it is generally accepted that the best mechanical properties are achieved when the photoactivation is performed immediately after mixing base and catalyst, ${ }^{20}$ this was not particularly true for MaxCem Elite when in contact with HAp. When cementing indirect restorations, luting cements must set in a practically short time to resist clinical stresses when cemented to the remaining tooth structure. For this reason, an immediate photoactivation is usually performed to optimize the initial cement properties. ${ }^{5,21}$ Although lower percentages of conversion in self-curing mode in the case of light attenuation would be expected, ${ }^{10}$ an additional glass ionomer-type reaction is claimed to simultaneously occur associated with free radical polymerization. ${ }^{22}$ Therefore, other setting reactions seem to contribute to the overall cement properties. This somehow explains why some resin cements are dependent on photoactivation and others are dependent on the chemical activation depending on a variety of parameters tested.., 23

Besides the polymerization condition (dual-cure or selfcure), in the case of the self-adhesive resin cements, it is important to consider its complex curing mechanism, in which the HAp has an essential involvement. ${ }^{1,24,25}$ Common formulations of self-adhesive resin cements include methacrylate monomers modified with 4-MET (methacryloyloxyethyl trimellitic acid) and 10-MDP (10-methacryloyloxydecyl dihydrogen phosphate). ${ }^{26}$ Also, new formulations of acid-modified methacrylate phosphates including GDMP (glycerol-phosphate dimethacrylate), MEP (methacryloyloxyethyl dihydrogen phosphate), penta-P (dipentacrythical pentaacrylate monophosphate), and phenyl-P (2-methacryloxyethyl phenyl hydrogen phosphate) were also introduced. ${ }^{1,26}$ Other carboxylic acid monomers such as 4-META (anhydride form of 4-MET) and PMGDM (pyromellitic glycerol dimethacrylate) are also added to self-adhesive formulations. ${ }^{27}$ It has been generally accepted that these category of materials is able to provide ionic and covalent interaction between the cement and the dental tissues, which may then form a salt complex between calcium and the acid-modified monomer. In the present study, cements were mixed with HAp with a high degree of crystallinity and purity to in vitro simulate such interaction with the dental tissues.

Flexural strength and flexural modulus ( - Tables 2 and $\mathbf{3}$ ) were used in this study as indicators for mechanical properties of the materials according to the polymerization condition. The results of the flexural test demonstrated significant differences among the materials, confirming the dissimilarity in terms of material properties in this class of material. In the presence of HAp, the activation mode of the cement did not significantly influence the mechanical properties of any cement, except the flexural modulus of Maxcem Elite. In the absence of HAp, both flexural strength and flexural modulus of RelyX U200 and the flexural modulus of Maxcem Elite were significant affected. Therefore, the presence of HAp resulted in similar or significantly higher mechanical properties compared with groups without HAp, regardless of the form of activation. Therefore, in a general view it was evident that in the groups that the $\mathrm{pH}$ neutralization was more efficient over the first 24 hours tend to reach better mechanical properties. It is known that remaining acidic monomers are less reactive than unmodified methacrylates, ${ }^{6}$ yielding lower polymerization rate and $\mathrm{C}=\mathrm{C}$ conversion potential, which could importantly impact in the mechanical properties of the material. In the present study, the HAp powder was mixed with the 
cements, which seems to explain why flexural strength and modulus were positively affected.

Despite the variations in $\mathrm{pH}$ neutralization ratio and mechanical properties of the cements, the depth of cure was not importantly affected by the polymerization condition. All materials presented polymerization depth $>5 \mathrm{~mm}$, which is not clinically impacting (-Table 4). On the other hand, it has been claimed that differences in the mechanical properties may predict the in vivo variations on the longevity of the clinical success of indirect restorations. ${ }^{11}$ In addition, it has been demonstrated that cements in which $\mathrm{pH}$ neutralization is not effective may display higher hydrophilicity and higher hygroscopic expansion stress. ${ }^{28}$

It could be argued that in a clinical scenario, the interaction of the cement and HAp is limited to the interface. In a previous study, ${ }^{29}$ it was demonstrated that self-adhesive resin cements present a limited decalcification/infiltration into the underlying dentin HAp. It was also found that the self-adhesive cements tested were not able to completely demineralize and dissolve the underlying smear layer.. ${ }^{29}$ Also, the acidic monomers incorporated in the self-adhesive resin cements were found to be not strong enough to acid-etch through smear layers, forming a no-authentic hybrid layer along the resin-tooth interface. ${ }^{17}$ Conversely, these limitations seem to be overcome by the formation of chemical bonds between the dentin and acidic functional monomers-containing self-adhesive resin cements. ${ }^{26}$ For that, characteristics such as viscosity, wetting ability of cement, and characteristics of the substrate, among others, may also contribute for the effectiveness of the bonding. ${ }^{30,31}$ In the present study, a minimal amount of HAp powder was mixed with the self-adhesive cements. In this way, the results of the present study seem to indicate that the mechanical properties and the depth of cure of self-adhesive resin cements may be positively affected when in contact with the dentin HAp.

This study investigated the influence of different activation protocols on the $\mathrm{pH}$ neutralization, mechanical properties, depth of cure, and changes in the chemical bonds when commercial self-adhesive cements were mixed to pure HAp. It was demonstrated that both factors influenced some of the results, based on the different parameters evaluated. In the present study, clinical relevant issues were discussed, considering the simplification of clinical steps when using self-adhesive cements. Based on the results, it was demonstrated that the effectiveness of self-adhesive cements occurs when these materials are able to demineralize the tooth structure, chemically react with the HAp, and simultaneously polymerize with a higher degree of conversion when their final $\mathrm{pH}$ is neutralized. The correct use of these materials is imperative to successfully finalize a restorative procedure, as a detailed clinical sequence needs to be considered. For the development of future self-adhesive cements, studies are necessary to guarantee a mechanical stability of self-adhesive resin cements when this category of luting agents is used for cementing indirect restorations.

\section{Conclusions}

According to the results of this in vitro study, it can be concluded that the aggressiveness of the self-adhesive resin cements, demonstrated by the quantified $\mathrm{pH}$ variation, varied among the materials with a tendency for neutralization. Also, MaxCem Elite when photoactivated was the only cement influenced by the addition of the HAp in terms of mechanical properties. The self-adhesive cements tested presented similar depth of cure based on the ISO 4049 parameters, irrespective of the evaluated factors. In general, self-adhesive cement properties evaluated remained unaltered or improved when mixed with HAp, irrespective of the activation mode, demonstrating that clinical conditions in which the cementation is performed in the absence of HAp, the performance of the self-adhesive cement tested are not affected.

\section{Funding}

None.

\section{Conflict of Interest}

None declared.

\section{Acknowledgments}

The authors are grateful to Universidade Anhanguera de São Paulo (UNIAN-SP) for the technical support. This study was developed as partial fulfillment of the requirements of Dr. Camargo's PhD degree.

\section{References}

1 Ferracane JL, Stansbury JW, Burke FJ. Self-adhesive resin cements - chemistry, properties and clinical considerations. J Oral Rehabil 2011;38(4):295-314

2 Radovic I, Monticelli F, Goracci C, Vulicevic ZR, Ferrari M. Self-adhesive resin cements: a literature review. J Adhes Dent 2008;10(4):251-258

3 Moszner N, Salz U, Zimmermann J. Chemical aspects of self-etching enamel-dentin adhesives: a systematic review. Dent Mater 2005;21(10):895-910

4 De Munck J, Vargas M, Van Landuyt K, Hikita K, Lambrechts P, Van Meerbeek B. Bonding of an auto-adhesive luting material to enamel and dentin. Dent Mater 2004;20(10):963-971

5 D’Alpino PH, Silva MS, Vismara MV, Di Hipólito V, Miranda González AH, de Oliveira Graeff CF. The effect of polymerization mode on monomer conversion, free radical entrapment, and interaction with hydroxyapatite of commercial self-adhesive cements. J Mech Behav Biomed Mater 2015;46:83-92

6 Adusei GO, Deb S, Nicholson JW. A preliminary study of experimental polyacid-modified composite resins ('compomers') containing vinyl phosphonic acid. Dent Mater 2005;21(6):491-497

7 Moraes RR, Boscato N, Jardim PS, Schneider LF. Dual and self-curing potential of self-adhesive resin cements as thin films. Oper Dent 2011;36(6):635-642

8 D’Alpino PH, Moura GEDD, Barbosa SCA, et al. Differential cytotoxic effects on odontoblastic cells induced by self-adhesive resin cements as a function of the activation protocol. Dent Mater 2017;33(12):1402-1415 
9 Manso AP, Carvalho RM. Dental cements for luting and bonding restorations: Self-adhesive resin cements. Dent Clin North Am 2017;61(4):821-834

10 Vrochari AD, Eliades G, Hellwig E, Wrbas KT. Curing efficiency of four self-etching, self-adhesive resin cements. Dent Mater 2009;25(9):1104-1108

11 Zorzin J, Petschelt A, Ebert J, Lohbauer U. pH neutralization and influence on mechanical strength in self-adhesive resin luting agents. Dent Mater 2012;28(6):672-679

12 Madruga FC, Ogliari FA, Ramos TS, Bueno M, Moraes RR. Calcium hydroxide, $\mathrm{pH}$-neutralization and formulation of model self-adhesive resin cements. Dent Mater 2013;29(4):413-418

13 D'Alpino PH, Svizero NR, Carrilho M, Self-adhering composites. In: Miletic V, ed. Dental Composite Materials for Direct Restorations. Cham: Springer International Publishing; 2018:129-151

14 Chaves FO, Farias NC, Medeiros LM, Alonso RC, Di Hipólito V, D'Alpino PH. Mechanical properties of composites as functions of the syringe storage temperature and energy dose. J Appl Oral Sci 2015;23(2):120-128

15 Pereira SG, Fulgêncio R, Nunes TG, Toledano M, Osorio R, Carvalho RM. Effect of curing protocol on the polymerization of dual-cured resin cements. Dent Mater 2010;26(7):710-718

16 Zhang Y, Wang Y. Hydroxyapatite effect on photopolymerization of self-etching adhesives with different aggressiveness. J Dent 2012;40(7):564-570

17 Di Hipólito V, Azevedo LD, Piveta FB, et al. Effect of dentinal surface preparation on the bonding of self-adhesive luting cements. J Adhes Sci Technol 2014;28:1901-1924

18 Vaz RR, Hipólito VD, D'Alpino PH, Goes MF. Bond strength and interfacial micromorphology of etch-and-rinse and self-adhesive resin cements to dentin. J Prosthodont 2012;21(2):101-111

19 Han L, Okamoto A, Fukushima M, Okiji T. Evaluation of physical properties and surface degradation of self-adhesive resin cements. Dent Mater J 2007;26(6): 906-914

20 Saskalauskaite E, Tam LE, McComb D. Flexural strength, elastic modulus, and $\mathrm{pH}$ profile of self-etch resin luting cements. J Prosthodont 2008;17(4):262-268
21 Pegoraro TA, da Silva NR, Carvalho RM. Cements for use in esthetic dentistry. Dent Clin North Am 2007;51(2): 453-471, x x

22 Nakamura T, Wakabayashi K, Kinuta S, Nishida H, Miyamae $\mathrm{M}$, Yatani H. Mechanical properties of new self-adhesive resin-based cement. J Prosthodont Res 2010;54(2):59-64

23 Cota AO, Caetano AF, Barbosa SC, et al. The effect of polymerization mode on mechanical properties of commercial self-adhesive cements associated with hydroxyapatite. J Adhes Sci Technol 2017;31:1635-1646

24 Makkar S, Malhotra N. Self-adhesive resin cements: a new perspective in luting technology. Dent Update 2013;40(9):758-760, 763-764, 767-768

25 Polassi MR, Almeida RM, Barbosa SC, Svizero NR, D’Alpino PH. Bonding ability of self-adhesive resin-cements after dentin biomodification with hyaluronic acid. J Adhes Sci Technol 2018;32:1033-1043

26 Fukegawa D, Hayakawa S, Yoshida Y. Suzuki K, Osaka A, Van Meerbeek B. Chemical interaction of phosphoric acid ester with hydroxyapatite. J Dent Res 2006;85(10):941-944

27 Yoshida Y, Nagakane K, Fukuda R, et al. Comparative study on adhesive performance of functional monomers. J Dent Res 2004;83(6):454-458

28 Roedel L, Bednarzig V, Belli R, Petschelt A, Lohbauer U, Zorzin J. Self-adhesive resin cements: pH-neutralization, hydrophilicity, and hygroscopic expansion stress. Clin Oral Investig 2017;21(5):1735-1741

29 Monticelli F, Osorio R, Mazzitelli C, Ferrari M, Toledano M. Limited decalcification/diffusion of self-adhesive cements into dentin. J Dent Res 2008;87(10):974-979

30 Ferrari M, Carvalho CA, Goracci C, et al. Influence of luting material filler content on post cementation. J Dent Res 2009;88(10):951-956

31 Pedreira AP, D'Alpino PH, Pereira PN, et al. Effects of the application techniques of self-adhesive resin cements on the interfacial integrity and bond strength of fiber posts to dentin. J Appl Oral Sci 2016;24(5):437-446 